\title{
Nonlinear Progressive Failure Analysis of Surrounding Rock System Based on Similarity Theory
}

\author{
Y. Zhao ${ }^{1,2}$, and L. He \\ ${ }^{1}$ College of Civil Engineering, Chongqing University, China \\ ${ }^{2}$ Key Laboratory of New Technology for Construction of Cities in Mountain Area( Chongqing University ), Ministry of Education, China
}

\begin{abstract}
Nonlinear progressive failure study of surrounding rock is important for the stability analysis of underground engineering projects. Taking a deep-buried tunnel in Chongqing as an example, a three dimensional(3-D) physical model was established based on similarity theory. To satisfy similarity requirement of physical-mechanical properties, such as elastic modulus, compressive strength and Poisson ratio, physical model materials were developed. Using full inner-spy photograph technology, the deformation and failure process of rock were studied under the situation of independent and combined action of anchor, shotcrete and reinforcing mesh. Based on experimental results, the interaction mechanism between rock and support structure under high stress was investigated.
\end{abstract}

\section{Introduction}

Rock system is a typical multi-components material, which consists of rock block, fracture and other components. Under the deep buried conditions, rock deformation may not belong to elasticity range, the interaction mechanisms of physical nonlinear and geometric nonlinear will make the evolution of rock system extremely complicated [1-3]. Similarity theory has been proved to be very useful to solve the problem [4-5]. As a significant method of science research, physical model test is the first introduced model which similar to the prototype in laboratory based on the similarity principles, by observing mechanical parameters and distribution of model with instrument, then deduce possible mechanics phenomenon and pressure distribution of the prototype with results of model, finally solve practical problems of rock engineering. This research method is simple, intuitive, economic and fast, as well as its period is short.

Using model test, displacement back analysis and boundary element calculation, Chi Yong et al. studied the stability of full seam gateway supported with anchor, and his research reflected good combination of model test with numerical calculation [6]. Chen Anming et al. developed a creep equation for soft rock materiel to study the model test of soft rock reinforced anchor cable, and discussed the variation of tension force of anchor cable with time [7]. Zhu Fangcai et al. studied rock burst character of similar material failure under different stress paths for underground tunnel [8]. Li Zhongkui et al. did a lot of meaningful researches on 3-D model simulation technology [9]. However, some strength indexes (like cohesive force, internal friction angle, tensile strength), the physical and mechanical properties of post-peak rock (like residual cohesive force, residual internal friction angle) are considered rarely, which makes it difficult to identify the failure mechanisms of rock mass [5].

This paper studied the stability of surrounding rock for deep-buried long tunnel by physical model test on true triaxial apparatus designed by Institute of Rock and Soil Mechanics, Chinese Academy of Sciences. Based on available materials, new similarity materials were compounded by ameliorating present prescription. The indexes of physical and mechanical properties of materials compounded in this study, such as compression strength, tensile strength, Poisson's ratio, internal friction angle, meet the requirement of similarity relation, stimulate high geostress field of deep-buried tunnel, perform the 3-D physical model tests of three-centered arch cavity under the situation of independent and combined action of anchor, shotcrete and reinforcing mesh. Based on the experiment results, the paper studied the interaction mechanism between the evolution of rock deformation and support structure under high stress.

\section{Similarity theory}

In order to make the model and prototype have similar physical phenomena, materials, shape and load of model must follow the similarity principles of the prototype. For geomechanics model test, it must make the equilibrium equation, compatible equation, geometric equation, physical equation and boundary condition of model fully agree with the prototype, it also make the strain of model is the same as the prototype, and strength criterion and stress-strain relationship of model similar to the prototype. These similarity coefficients which defined as the ratios 
of prototype parameters to model parameters must be constants. In this work, subscripts $\mathrm{p}$ and $\mathrm{m}$ denote prototype parameters and physical models parameters, respectively, and then these similarity constants can be defined as:

$$
\begin{gathered}
C_{l}=\frac{l_{p}}{l_{m}}, C_{v}=\frac{v_{p}}{v_{m}}, C_{\gamma}=\frac{\gamma_{p}}{\gamma_{m}} \\
C_{\sigma}=\frac{\sigma_{p}}{\sigma_{m}} C_{E}=\frac{E_{p}}{E_{m}} C_{\varepsilon}=\frac{\varepsilon_{p}}{\varepsilon_{m}} \\
C_{C}=\frac{C_{p}}{C_{m}}, C_{\varphi}=\frac{\varphi_{p}}{\varphi_{m}}
\end{gathered}
$$

where $C_{l}, C_{v}, C_{\gamma}, C_{\sigma}, C_{E}, C_{\varepsilon}, C_{C}$ and $C_{\varphi}$ indicate similarity constants for geometry, Poisson's ratio, density, stress, elastic modulus, rain, cohesion force and internal friction angle similarity constant, respectively.

And following similarity equations are described as:

$$
\begin{gathered}
C_{E}=\frac{C_{\sigma}}{C_{\varepsilon}} \\
\frac{C_{\sigma}}{C_{l} C_{\gamma}}=1 \\
\frac{C_{c}}{C_{l} C_{\gamma}}=1, \frac{C_{\varphi}}{C_{l} C_{\gamma}}=1 \\
C_{\varepsilon}=1, C_{\gamma}=1
\end{gathered}
$$

In practical application, it is difficult to get complete similarity model which all similarity principles are satisfied, so the model just need to meet the main similarity principles.

All aspects should be considered for the test accuracy, such as the test load and economic indexes of the model, suitable model materials which are difficulty to search, the test technology and simulation range of existing equipment. Therefore, it should analysis multiple schemes of model scale to ensure the accuracy, then the parameters finally selected are shown in Table 1.

Table 1. Similar scale of model test.

\begin{tabular}{|l|c|}
\hline \multicolumn{1}{|c|}{ Similarity constant } & Value \\
\hline$C_{l}$ & 50 \\
\hline$C_{\sigma}$ & 40 \\
\hline$C_{E}$ & 40 \\
\hline$C_{c}$ & 1 \\
\hline$C_{\phi}$ & 1 \\
\hline$C_{v}$ & 1 \\
\hline
\end{tabular}

\section{Simulation of prototype model}

The physical model size is $80 \mathrm{~cm} \times 80 \mathrm{~cm} \times 80 \mathrm{~cm}$ (as shown in Fig. 1). The model is poured by four stratums, and thickness of each stratum is $20 \mathrm{~cm}$. Anchors are established in the second, third and fourth stratums. The most length of long anchor in the second and third stratums is $82 \mathrm{~mm}$, while short anchor is $55 \mathrm{~mm}$. In the fourth stratum, the length of long anchor is $110 \mathrm{~mm}$, while short anchor is $91 \mathrm{~mm}$. Lining is established in the third and fourth stratums (as shown in Fig. 2). Lining is established in the third and fourth stratums, the thickness is $5 \mathrm{~mm}$ (as shown in Fig. 3).

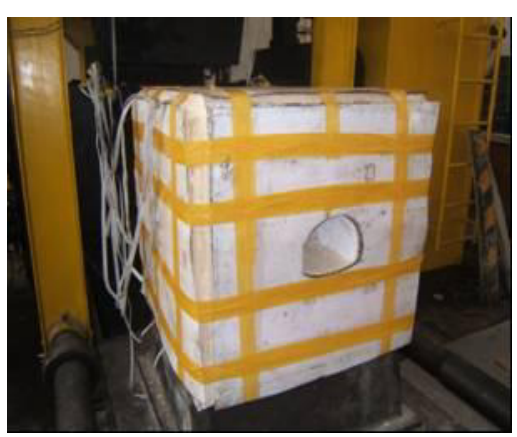

Figure 1. Three-dimension model.

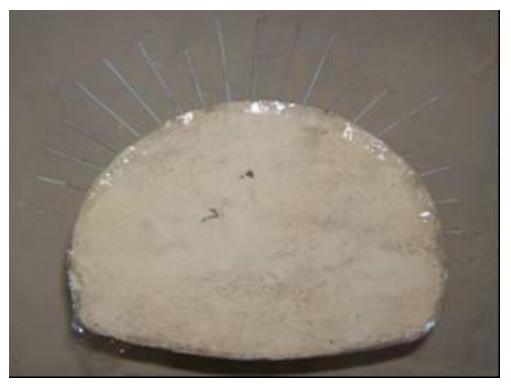

Figure 2. Anchor arrangement.

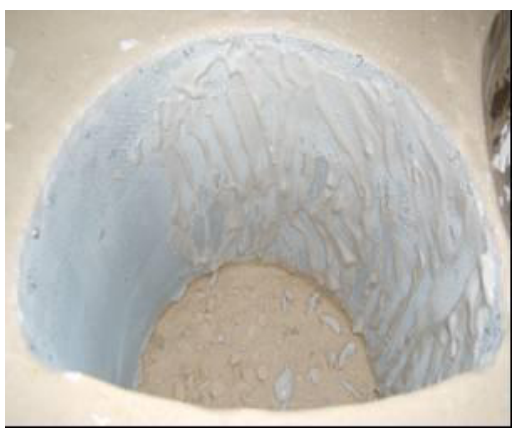

Figure 3. Initial lining.

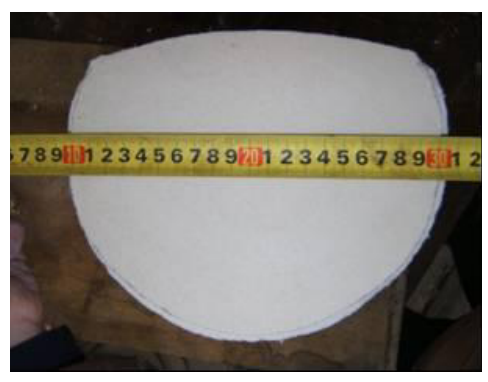

Figure 4. Thickness of initial lining. 


\section{Model test and results analysis}

\subsection{Steps of loading}

The ratio of horizontal load to vertical load in this test is 0.8 . The horizontal load ( $\mathrm{X}$ direction) and the vertical load ( $\mathrm{Z}$ direction) start with $200 \mathrm{KN}$ and $250 \mathrm{KN}$, respectively, and then are elevated by $40 \mathrm{KN}$ and $50 \mathrm{KN}$ step by step, respectively. When elevated to $400 \mathrm{KN}$ and $500 \mathrm{KN}$, the load for horizontal load per step is elevated by $20 \mathrm{KN}$ and vertical load by $25 \mathrm{KN}$. When the horizontal and vertical load is increased to $1120 \mathrm{KN}$ and $1400 \mathrm{KN}$, respectively, stop loading.

\subsection{Results analysis}

(1) The first stratum: cavity without any support

Middle vault collapse is the main failure form for cavity, and the thickness of collapse pieces is about 20 $\mathrm{mm}$. The bottom of arch is generally in good conditions. And the horizontal displacement of sidewalls is dominant for the surrounding rock; the maximum value is about $7 \sim 8 \mathrm{~mm}$ appearing in the area between arch waist and arch feet (as shown in Fig. 5).

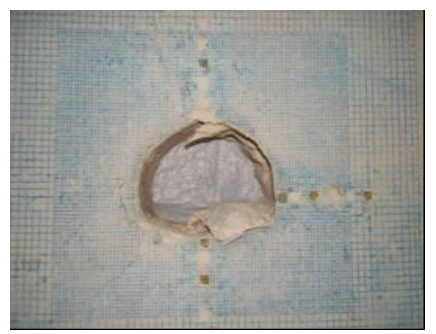

Figure 5. Failure of the first stratum.

The height of disturbed zone is about $0.5 \mathrm{D}$ (D indicates the radius of the cavity). Vertical downward displacement occurs above arch waist (including surrounding rock of the vault), and the height of affected zone in vault is about 0.6 D. The maximum displacement is at vault and the value is about $3 \mathrm{~mm}$. Vertical upward displacement occurs below the bottom of arch, but the affected zone is roughly $0.1 \sim 0.2 \mathrm{D}$ smaller. Two big cracks and a fractured zone occurred in surrounding rock, one of the two big cracks develops from the collapse area of vault to the model boundary, while the other crack develops from the collapse area of arch feet to the model boundary is about $45^{\circ}$. Fractured zone appears in the area from arch waist to arch feet, the deepest thickness of these zones is about $25 \mathrm{~mm}$.

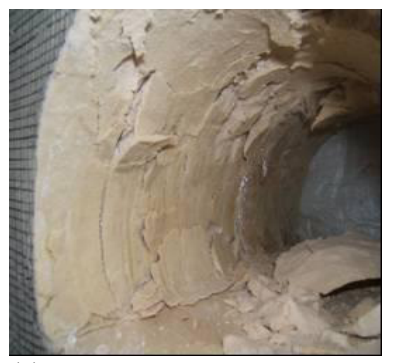

(a)

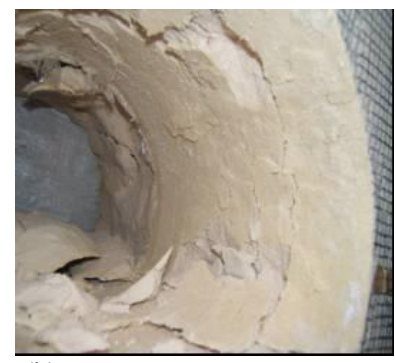

(b)

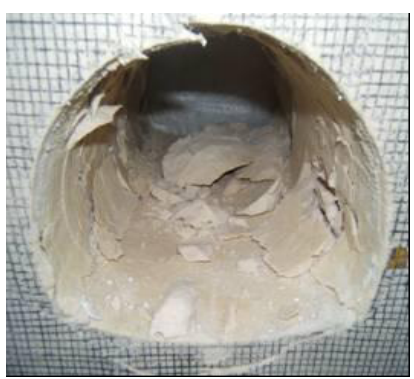

(c)

Figure 6. Failure of the second stratu.

(2) The second stratum: anchor only supportsarch waist applied above

Vertical rhegma of sidewalls is the main failure form. Loading causes spalling, the thickness of chunks of rock seperating is about $8 \mathrm{~mm}$ in the position of arch foot. Vault and bottom of arch are nearly intact (as shown in Fig. 6).

The horizontal displacement is the main deformation of surrounding rock, and the maximum value which appears at arch feet is about $5 \mathrm{~mm}$. The deformation is focused on some regions nearby arch feet, and the depth influenced is about $0.3 \mathrm{D}$. The deformation above arch feet is not obvious. The maximum vertical upward displacement occurring in arch feet is maximum vertical displacement and the value is about $5 \mathrm{~mm}$. The vault's vertical downward displacement is relatively small, and the value is about $1 \sim 2 \mathrm{~mm}$. In addition, a vertical crack develops from vault to model boundary.

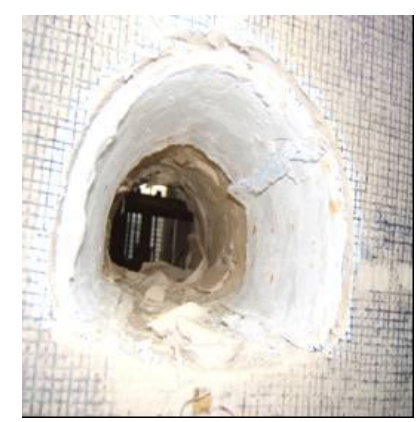

Figure 7. Failure of the third stratum.

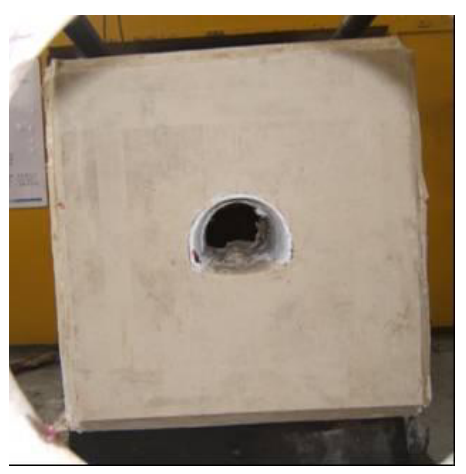

Figure 8. Failure of the forth stratum.

(3) The third stratum: On the basis of the second stratum, a lining is established above arch feet. A fine iron wire net is placed in lining. 
The horizontal displacement is dominant for the surrounding rock, and the maximum value appears in arch waist, is about $2 \sim 3 \mathrm{~mm}$. The vertical displacement is small. Some small pieces of bursting cracks occur in bottom of arch (as shown in Fig.7). Spray layer is nearly intact, except a leap (the fine iron wire net completely exposes) parallel cavity axis appears in the middle part of a side between vault and arch waist (as shown in Fig.7). In addition, two approximately paralle vertical cracks occur in one side of vault.

(4) The fourth stratum: anchor support arch waist applied above, and the length of anchors is longer than the third. The anchors of $55 \mathrm{~mm}$ in the third stratum are lengthened to $91 \mathrm{~mm}$, while anchors of $82 \mathrm{~mm}$ are lengthened to 110 $\mathrm{mm}$. And the spray layer is the same as the third stratum

There is no failure in the surrounding rock. And the spray layer does not break off from surrounding rock (as shown in Fig.8).

\section{Discussion and conclusions}

The deformation, failure depth and affected region in the first stratum are the most outstanding, but the bottom of arch remains nearly intact. In the second stratum, the failure region is less than the first stratum, and only a small slump occurs in the surface area of the vault, the tangential stress of side walls decreases significantly. It shows that mechanical anchoring effect increases with the decreasing of disturbed zone. In the third stratum, the main failure of cave walls is the crack at the bottom of arch and the leap of spray layer; the other depth failure is less. The fourth stratum has no failure phenomenon, it is more stable than first three stratums.

Comparing among these four stratums, it can conclude that failure deformation of cavity without any support is the largest. Many rock units are in the postfailure regions according to the peak stress. The residual strength is determined by friction between strips. It develops a new rock of mechanics boundary, which makes rock's property close to loose massive media, and determines rock pressure and residual strength. The existence of the residual strength has great influence on stability of deep-buried tunnel under high rock pressure.

After applying anchor to support arch waist, the stability of cave walls is good. There is almost no axial crack and fall-block, and the cracks mainly occur in weak section between anchors. Large cracks connecting the two arch feet occur in the bottom of arch with no any reinforce measures, which belongs to integral failure. When support is provided by rock bolts and shotcrete, failure occurs in the spray layer and the bottom of arch, but the surrounding rock is nearly intact, further increase the length of anchors, the stability of the surrounding rock is in a good condition.

\section{Acknowledgments}

This work was supported by the New Century Excellent Talent Foundation from MOE of China(Grant No. NCET-09-0844), the Fundamental Research Funds for the Central Universities (Grant No.CDJZR11 2000 14), and National Natural Science Foundation of China (Grant No.50804060).

\section{References}

1. Shi X.Z., Zhou J., Li X.B., Utilization of a nonlinear support vector machine to predict blasting vibration characteristic parameters in opencast mine, Przegląd Elektrotechniczny, 88 127-132 (2012)

2. Ren L., Zhao J.Z., Hu Y.Q., Wang L., Effect of natural fractures on hydraulic fracture initiation in cased perforated boreholes, Przegląd Elektrotechniczny, 88 108-112 (2012)

3. Zhao Y., Peng H.Y., Analysis of nonlinear dynamic character in the surrounding rock system for deep buried underground engineering, Journal of Coal Science and Engineering (China), 16, 4 362-366 (2010)

4. Liu J., FengX.T., DingX.L., ZhangJ., Yue D.M., Stability assessment of the Three-Gorges Dam foundation, China,using physical and numerical modeling-Part I: physical model tests, International Journal of Rock Mechanics \& Mining Sciences, 40, 5 609-631 (2003)

5. Zhao Y., Peng H.H., Experimental study on similarity materials for soft rock of deep-buried tunnels, Journal of Coal Science \& Engineering (China), 17, 2 124-127 (2011)

6. Chi Y., Zhou J., Kang J.H., Simulation analysis of stability of coal roadway bolting, Mining and Metallurgical Engineering, 22, 1 39-41 (2002)

7. Chen A.M., Gu J.C., Shen J., Ming Z.Q., Model testing research on the variation of tension force of anchor cable with time in reinforcement of soft rocks, Chinese Journal of Rock Mechanics and Engineering, 21, 2 251-256 (2002)

8. Zhu F.C., Study on failure models of simulated material under different stress paths, Journal of Central South University of Technology, 33, S 8-11 (2002)

9. Li Z.K., Lu D.R., Nakayama H., Hosomi H., Sun J.S., Development and application of new technology for $3 \mathrm{~d}$ geo-mechanics model test of large underground houses, Chinese Journal of Rock Mechanics and Engineering, 22, 9 1430-1436 (2003) 